\title{
Herbal medicine use during breastfeeding: a cross-sectional study among mothers visiting public health facilities in the Western area of Sierra Leone
}

\author{
Peter Bai James ${ }^{1,2^{*}}$ (D) Angela Isata Kaikai ${ }^{2}$, Abdulai Jawo Bah ${ }^{2,3}$, Amie Steel $^{1,4}$ and Jon Wardle ${ }^{1}$
}

\begin{abstract}
Background: The use of medications, including herbal medicines during breastfeeding is always a concern among women. Currently, there is no published evidence on whether Sierra Leonean women use herbal medicine during breastfeeding. This study investigates the prevalence, correlates and pattern of herbal medicine use during breastfeeding.

Methodology: We conducted a cross-sectional study among 378 current breastfeeding mothers visiting public healthcare facilities within the Western area of Sierra Leone. Descriptive statistics and logistic regression analysis were used for data analysis.

Results: Over a third of mothers ( $n=140,37.0 \%)$ used herbal medicine during breastfeeding. However, very few herbal medicine users $(2.1 \%, n=3)$ used herbal medicine to augment breastfeeding. Dietary changes were the most common method used to increase breast milk supply $(93.9 \%, n=355)$ with cassava leaves sauce and tubers being the most common dietary addition. Mothers with children more than six months old were more likely to use herbal medicine than mothers with younger children (OR:1.8; Cl:1.13-2.85, $p=0.013)$. Among herbal medicine users, only $11.4 \%(n=16)$ disclosed their herbal medicine use to their conventional healthcare providers.

Conclusion: The use of herbal medicine among breastfeeding mothers attending public health facilities in the Western area of Sierra Leone is common. Whilst this use is not usually specific to increasing breast milk supply, our study indicates that herbal medicines may be used to 'cleanse' initial breast milk.
\end{abstract}

Keywords: Herbal medicine, Lactation, Prevalence, Maternal health, Sierra Leone

\section{Background}

The worldwide use of traditional complementary and alternative medicine (TCAM) has grown considerably in recent decades [1]. Herbal medicines are a widely used form of TCAM, especially in Africa $[2,3]$ due to their affordability, accessibility and cultural significance [4]. Previous research has demonstrated that women, more than men, use TCAM [5-7]. Much of this utilisation centres on reproductive health for conditions and life

\footnotetext{
* Correspondence: Peter.B.James@student.uts.edu.au

${ }^{1}$ Australian Research Centre in Complementary and Integrative Medicine, Faculty of Health, University of Technology Sydney, Ultimo, Sydney, NSW 2007, Australia

${ }^{2}$ Faculty of Pharmaceutical Sciences, College of Medicine and Allied Health Sciences, University of Sierra Leone, Freetown, Sierra Leone

Full list of author information is available at the end of the article
}

stages such as infertility, amenorrhea, birth control, pregnancy, childbirth and postpartum healthcare including lactation [8-12]. International studies in Australia [13], Italy [14] and Taiwan [12] have also demonstrated a high use of herbal medicines during breastfeeding. Despite the high use of herbal medicines for breastfeeding, and increased interest of herbal medicine research and maternal and child health research in Africa, there has not been significant focused attention on herbal medicine use during breastfeeding in Africa. Self-reported reasons for women's use of herbal medicines are: the belief that it is natural and therefore safe; feeling in control of one's health; increased accessibility; cost, or dissatisfaction with conventional healthcare $[15,16]$. However, despite evidence of high utilization, evidence of efficacy and safety

(c) The Author(s). 2019 Open Access This article is distributed under the terms of the Creative Commons Attribution 4.0 International License (http://creativecommons.org/licenses/by/4.0/), which permits unrestricted use, distribution, and reproduction in any medium, provided you give appropriate credit to the original author(s) and the source, provide a link to the Creative Commons license, and indicate if changes were made. The Creative Commons Public Domain Dedication waiver (http://creativecommons.org/publicdomain/zero/1.0/) applies to the data made available in this article, unless otherwise stated. 
for herbal medicines during breastfeeding remains inconclusive [17], and - as with any medication use in breastfeeding - there is the potential for maternal and infant harm due to inherent toxicity, herb-drug interactions [18] or heavy metal contamination $[19,20]$.

Early cessation of breastfeeding due to insufficient milk production [21] is often a reason for the use of breast milk substitutes or women to use complementary medicine approaches believed to increase breast milk production and supply $[12,22]$. The use of herbal galactagogues, kangaroo mothering, acupuncture, massage and relaxation $[22,23]$ are often considered to be cheaper, safer and culturally acceptable TCAM options to conventional medicine for improving milk supply [24]. Herbal remedies during breastfeeding are also utilised for the 'cleansing' of breast milk (which some mothers may consider 'dirty' at the initial stage of lactation) or to maintain the general health and wellbeing of the mother [25].

Sierra Leonean studies have shown herbal medicine to be commonly used to treat malaria and febrile illness, [26], sick children [27],pregnant women [28], hypertensive patients [29] and general health in student populations [30, 31]. Given such high utilisation rate in sub-health populations in Sierra Leone, and the high utilisation of herbal medicine use for breastfeeding in other countries, it can be speculated that a similar pattern will be observed among breastfeeding mothers in Sierra Leone. This hypothesised pattern may be impacted by the introduction of the free healthcare initiative (FHCI) for pregnant women, lactating mothers and under-five children launched in Sierra Leone in 2010, which removed cost for healthcare service as a barrier to accessing care in public health facilities [32]. This may impact TCAM's advantage as the lower cost form of healthcare. However, a recent report indicates that despite this new scheme, women are still paying for conventional health services [33]. Meanwhile, much of the production, distribution, use and practice of traditional medicines remains unregulated in Sierra Leone [34], which may facilitate easier access than regulated services.

Currently, little is known about herbal medicine use during breastfeeding in Africa with no such study conducted in Sierra Leone. Most studies on herbal medicine in maternal and child health have focused on use during pregnancy [9, 28, 35, 36], fertility [8] general women's health $[11,37]$. This study aims to begin to address this knowledge gap by investigating the prevalence, determinants and pattern of use of herbal medicine during breastfeeding among mothers visiting public health facilities in the Western area of Sierra Leone.

\section{Methods}

\section{Study area and population}

The study area was the Western Area (WA) of Sierra Leone. WA comprises the Sierra Leonean capital city
(Freetown), and has a population of 1,493,252 of which $70 \%$ resides in the capital city [38]. WA is composed of the western rural district and urban Freetown. There are eight public hospitals in WA - all of which are located in Freetown - and 60 peripheral health clinics (community health centers or posts). Four of the public health hospitals and all of the peripheral health units provide postnatal care services.

\section{Study design and sample size determination}

A descriptive cross-sectional study was conducted among currently breastfeeding mothers who were 18 years of age and older, having a child 12 months old or younger, receiving care for them and/or their child at the designated healthcare facilities and who consented to take part in the study. The age span of study participants was $18-49$ years. Type of care received by breastfeeding mothers and their children include preventive care practices such as childhood vaccination, nutrition, counselling on danger signs and home care. Breastfeeding mothers and their children also received care for conditions such as malaria, respiratory infections and gynaecological infections. We excluded women from this study if they were chronically ill. The study period was between August and October 2016. The sample size for this study was calculated using the formula for sample size determination for cross-sectional study $\mathrm{n}=\mathrm{Z}^{2} \mathrm{Pq} / \mathrm{d}^{2}$. Where $n$ is the required sample size, $P$ is the estimated proportion of use of herbal medicine during lactation (0.599); taken from a similar study conducted in Western Australia [13]. $q=1-P$ is the probability of those not using herbs i.e. (1-0.599), $\mathrm{Z}=$ value of test statistics corresponding to $95 \%$ confidence interval (1.96) and $d=$ degree of accuracy/standard error (0.05) which gives approximately 363 participants as the minimum sample size. We decided to recruit 400 to assuming $10 \%$ non-response rate.

\section{Sampling method}

A multistage sampling technique was used to initially select the health facilities and then the mothers visiting them. We chose eight health facilities in order to be representative of lactating mothers attending these public health facilities. Initially, we divided WA into two strata i.e. rural and urban. We chose the two main health centers in the rural district that cater for the majority of mothers and six health facilities in the urban district, four of which were hospitals and the remaining two were peripheral health centers. We purposfully chose these health facilities in order to get a fair representation of lactating mothers within the Western area of Sierra Leone. We employed a simple random sample method to target the required number of lactating mothers in each facility. Proportional representation based on the 
attendance rate was used to determine the number of participants in each health facility.

\section{Study questionnaire}

The questionnaire for this study was designed in English based on current literature on the use of herbal medicine among lactating mothers [12, 13, 14, 39]. With the assistance of a linguistic expert from the University of Sierra Leone, we translated the English version into Creole (widely spoken language in Sierra Leone) and back-translated into English to ensure consistency. Both versions were sent to local experts in public health, epidemiology, pharmacology and pharmacognosy that were not part of the study. We then piloted both versions of the questionnaire among 15 lactating mothers. We excluded their data in the final analysis. Slight changes on the final versions of the questionniare were made based on the feedbacks received from the pilot study and by the local experts. The essence of the questionnaire adaptation was for it to be in line with our study objectives and to fit our local setting.

The questionnaire (Additional file 1) comprised of four sections: Part 1 and 2 included items about participant demographic profile and family background characteristics (age, tribe, and religion, place of origin, occupation and educational status). Section 3 comprised of the pattern of use, types of herbal medicine used, and the reason for use; Section 4 survey items explored the sources of herbal medicine information resources, and participant's perception regarding herbal medicine use during breastfeeding.

\section{Data collection and measurement}

The data were collected either by face-to-face interview in Creole (widely spoken language in Sierra Leone) for those who were illiterate or through self-administration of the questionnaire for those who were literate. We trained four final year pharmacy students to assist with data collection. The study questionnaire was distributed together with a consent form to all lactating mothers. For those who were illiterate, the nature of the survey form was explained to them. Either signing or thumb printing the consent form indicated their agreement to participate in the study. Mothers who participated were assured of their confidentiality, and they had the option to opt out at any time while answering the questions.

Herbal medicine in this study refers to a single or combination of more than one herb, herbal material, and finished herbal product that contains an active ingredient, part of the plant or other plant material or combination. We also excluded vitamins or nutraceuticals. In addition, we excluded preparations taken as nutrients and or part of the regular diet. A botanist at the University of Sierra Leone confirmed the local and botanical names of herbal medicines mentioned by respondents in this study. We also cross-checked the identity with two textbooks on medicinal plants of Sierra Leone $[34,40]$ and with the African Plant Database [41]. Mothers currently breastfeeding were considered herbal medicine users if they took herbal medicine through oral, intravaginal or topical routes for breastfeeding -related or non-related purposes 12 months preceding the survey. Perception of herbal medicine use among lactating mothers was determined using five-point Likert scale responses ranging from strongly agree, agree, neutral to disagree and strongly disagree. Responses with the same degree of agreement or disagreement were grouped together as positive and negative responses respectively.

\section{Statistical analysis}

Data from filled questionnaires were coded and analyzed using Statistical Package for Social Sciences (SPSS) for Windows, Version 22 (Chicago Inc.). Categorical and continuous variables were represented in frequency, percentages, mean, and standard deviation respectively. We determined the prevalence of herbal medicine use as the proportion of mothers who used herbal medicine using the target population as the denominator. Bivariate analysis using Chi square or fisher exact tests were used to establish an association between socio-demographic and other related characteristics and herbal medicine use. We used a logistic regression model to determine possible socio-demographic and other related predictors of herbal medicine use. Independent variables in the bivariate analysis with $p$-value $\leq 0.2$ were entered into initial univariate analysis (model1) to calculate crude ORs with 95\% confidence interval. Demographic and health related characteristics whose $p$-values were less than 0.05 in the univariate analysis where entered into the multivariable analysis (model 2) to determine adjusted odd ratios.. We considered covariates in the multivariate model as an independent predictor(s) of herbal medicine use if its $p$-value was less than 0.05 .

\section{Ethical clearance}

The research and ethics committee of College of Medicine and Allied Health Sciences, University of Sierra Leone (COMAHS-USL) gave ethical approval before the start of the study.

\section{Results}

Out of the 400 mothers approached, 378 agreed to participate given a response rate of $94.5 \%$. Close to two-third of mothers were between the ages of 20-29 years $(n=233,61.6 \%)$, Muslims $(n=241,63.8 \%)$ and married $(n=238,63.0 \%)$. Socio-demographic and related factors related to herbal medicine use during breastfeeding are presented in Table 1. Perceived health status of the child $(p=0.044)$, the age of the child $(p=0.003)$ and 
Table 1 Socio- demographic and health related factors associated with herbal medicines use

\begin{tabular}{|c|c|c|c|c|c|}
\hline Characteristics & Variables & Users $n(\%)$ & Non-users $n(\%)$ & Total $n(\%)$ & $p$-value \\
\hline \multirow[t]{4}{*}{ Age Group } & $<20$ years & 19(13.6) & $42(17.6)$ & $61(16.1)$ & \multirow[t]{4}{*}{0.303} \\
\hline & 20-29 years & $84(60.0)$ & 149(62.6) & 233(61.6) & \\
\hline & 30-39 years & $35(25.0)$ & $46(19.3)$ & $81(21.4)$ & \\
\hline & $40-49$ years & $2(1.4)$ & $1(0.4)$ & $3(0.8)$ & \\
\hline \multirow[t]{2}{*}{ Religion } & Christian & $50(35.7)$ & $87(36.6)$ & 137(36.2) & \multirow[t]{2}{*}{0.870} \\
\hline & Muslim & $90(64.3))$ & 151(63.4) & $241(63.8)$ & \\
\hline \multirow[t]{3}{*}{ Marital status } & Single & $37(26.4)$ & $55(23.1)$ & $92(24.3)$ & \multirow[t]{3}{*}{0.434} \\
\hline & Married & $89(63.6)$ & 149(62.6) & $238(63.0)$ & \\
\hline & Co-habitating & $14(10.0)$ & $34(14.3)$ & $48(12.7)$ & \\
\hline \multirow[t]{2}{*}{ Place of Origin } & Outside of Western Area & 133(95.0) & 213(89.5) & $346(91.5)$ & \multirow[t]{2}{*}{0.063} \\
\hline & Western Area & $7(5.0)$ & $25(10.5)$ & $32(8.5)$ & \\
\hline \multirow[t]{2}{*}{ Tribe } & Temne & $57(40.7)$ & $93(39.1)$ & 150(39.7) & \multirow[t]{2}{*}{0.753} \\
\hline & Others & $83(59.3)$ & $145(60.9)$ & $228(60.3)$ & \\
\hline \multirow[t]{4}{*}{ Educational status } & Non-formal & $51(36.4)$ & $81(34.0)$ & 132(34.9) & \multirow[t]{4}{*}{0.178} \\
\hline & Primary & $8(5.7)$ & 11(4.6) & 19(5.0) & \\
\hline & Secondary & $73(52.1)$ & $116(48.7)$ & 189(50.0) & \\
\hline & Tertiary & $8(5.7)$ & $30(12.6)$ & $38(10.1 \%)$ & \\
\hline \multirow[t]{2}{*}{ Employment status } & Employed & $73(52.1)$ & 111(46.6) & 184(48.7) & \multirow[t]{2}{*}{0.301} \\
\hline & Un- employed & $67(47.3)$ & 127(53.4) & 194(51.3) & \\
\hline \multirow[t]{3}{*}{ Monthly income } & $<1$ million Leones & 135(96.4) & 228(95.8) & 363(96.0) & \multirow[t]{3}{*}{0.895} \\
\hline & 1-3.5millions Leones & $4(2.9)$ & $9(3.8)$ & $13(3.4)$ & \\
\hline & > 3.5million Leones & $1(0.7)$ & $1(0.4)$ & $2(0.5)$ & \\
\hline \multirow{2}{*}{$\begin{array}{l}\text { No of children do you have including } \\
\text { one currently being breastfed }\end{array}$} & One & $60(42.9)$ & 115(48.3) & 175(46.3) & \multirow[t]{2}{*}{0.304} \\
\hline & More than one & $80(57.1)$ & 123(51.7) & 203(53.7) & \\
\hline \multirow[t]{2}{*}{ Age in months of child currently being breastfed } & $0-6$ months & $85(60.7)$ & 179(75.2) & 264(69.8) & \multirow[t]{2}{*}{0.003} \\
\hline & 7-12 months & $55(39.3)$ & $59(24.8)$ & 114(30.2) & \\
\hline \multirow[t]{2}{*}{ Gender of child currently breastfed } & Male & $73(52.1)$ & 122(51.3) & 195(51.6) & \multirow[t]{2}{*}{0.868} \\
\hline & Female & $67(47.9)$ & $116(48.7)$ & 183(48.4) & \\
\hline \multirow[t]{2}{*}{ Is this your first child you have given birth to? } & Yes & $54(38.6)$ & 113(47.5) & 167(44.2) & 0.092 \\
\hline & No & $86(61.4)$ & 125(52.8) & 225(56.3) & \\
\hline Perceived health status of current child & Healthy & $79(56.4)$ & 159(66.8) & 238(63.0) & 0.044 \\
\hline & Sick & $61(43.6)$ & $79(33.2)$ & 140(37.0) & \\
\hline Mother perceived health status & Healthy & 133(95.0) & 232(97.5) & 365(96.6) & 0.202 \\
\hline & Sick & $7(5.0)$ & $6(2.5)$ & 13(3.4) & \\
\hline Living with your parent or partner's parent & Yes & $57(40.7)$ & $80(33.6)$ & 137(36.2) & 0.165 \\
\hline & No & $83(59.3)$ & 158(66.4) & $241(63.8)$ & \\
\hline Role of parent or partner's parent on mother's health & Greater influence & $99(70.7)$ & 167(70.2) & $266(70.4)$ & 0.911 \\
\hline & Little or no influence & $41(29.3)$ & $71(29.8)$ & 112(29.6) & \\
\hline Use of other product or special diet to increase & Yes & 131(93.6) & 224(94.1) & 355(93.9) & 0.830 \\
\hline breast mik production & No & $9(6.4)$ & 14(5.9) & $23(6.1)$ & \\
\hline Herbal medicine is efficacious than conventional medicine & Agree & $44(31.4)$ & $49(20.6)$ & $93(24.6)$ & 0.047 \\
\hline & Neutral & $2(1.4)$ & $7(2.9)$ & $9(2.4)$ & \\
\hline & Disagree & $94(67.1)$ & 182(76.5) & $276(73.0)$ & \\
\hline Herbal medicine is safer than conventional medicine & Agree & $42(30.0)$ & $480(20.2)$ & $90(23.8)$ & 0.092 \\
\hline & Neutral & $3(2.1)$ & $7(2.9)$ & 10(2.6) & \\
\hline & Disagree & $95(67.9)$ & 183(76.9) & $278(73.5)$ & \\
\hline
\end{tabular}

$\$ 1=$ SLL7500 at the time of conducting the study 
their perception of the efficacy of herbal medicine $(p=0.047)$ were the only socio-demographic and health related factors significantly associated with herbal medicine use.

The results of pattern of herbal medicine use is presented in Table 2. Over one-third ( $n=140,37.0 \%)$ of lactating mothers used herbal medicine during breastfeeding. However, very few breastfeeding mothers used herbal medicines to improve lactation $(n=3,2.1 \%)$. Most breastfeeding women in this study $(n=124,88.6 \%)$ did not disclose their use of herbs to their healthcare professional, largely because they did not think it was necessary. Sources of herbal medicine information among users were mainly relatives, friends and traditional medicine practitioners (Fig. 1).

Table 3 shows that most women used dietary approaches to augmenting lactation $(n=355,93.9 \%)$. Cassava leaf sauce and tubers $(n=286)$ was the most common special diet used by lactating mothers to augment breastmilk production and supply. The most common herbal medicines used by breastfeeding women in this study (see Table 4) were Cassia sieberiana DC. (Bitter medicine), 66 (36.5\%) and Luffa acutangula (L.) Roxb. (Rabena) 53 (29.3\%). The majority of breastfeeding women in this study believed that it was helpful and reported stomachache $(84.1 \%, n=58)$, and cleansing of the breast against 'contaminated milk' $(49 \%, n=29)$ as the main indication for herbal medicine use (see Table 4).

The result of multiple logistic regression model to determine the predictive factors for herbal medicine use during breastfeeding is shown in Table 5. Mothers whose child is more than six months old were more likely to use herbal medicine compared to those whose child is six

Table 2 Pattern of Herbal Medicine use

\begin{tabular}{|c|c|c|}
\hline Statements & Variables & $n(\%)$ \\
\hline \multirow{2}{*}{$\begin{array}{l}\text { Use of herb during breastfeeding } \\
(n=378)\end{array}$} & Yes & $140(37.0)$ \\
\hline & No & $238(63.0)$ \\
\hline \multirow{2}{*}{$\begin{array}{l}\text { If yes, was it to augment breast milk } \\
\text { production and supply }(n=140)\end{array}$} & Yes & $3(2.1)$ \\
\hline & No & 137(97.9) \\
\hline \multirow[t]{2}{*}{ Experience side effect $(n=140)$} & Yes & $4(2.9)$ \\
\hline & No & 136(97.1) \\
\hline \multirow[t]{3}{*}{ If Yes, types of side effect ${ }^{a}$} & Nausea and vomiting & $3(75.0)$ \\
\hline & Rash & $2(50)$ \\
\hline & Itching & $2(50)$ \\
\hline \multirow{2}{*}{$\begin{array}{l}\text { Disclosure to health professional } \\
(n=140)\end{array}$} & Yes & 16(11.4) \\
\hline & No & 124(88.6) \\
\hline Reason for non-disclosure & $\begin{array}{l}\text { Thought it was not } \\
\text { necessary }\end{array}$ & $124(100)$ \\
\hline \multirow{2}{*}{$\begin{array}{l}\text { Inquiry by healthcare provider about } \\
\text { herbal medicine use } n=378\end{array}$} & Yes & 161(42.6) \\
\hline & No & $217(57.4)$ \\
\hline
\end{tabular}

${ }^{a}$ more than one option was ticked months old or less (OR:1.80; CI:1.13-2.85, $p=0.013$ ). Mothers that agreed with the statement that herbal medicine is more effective than conventional medicine to use during breastfeeding were more likely to use herbal medicine than those that disagreed although not statistically significant (OR:2.27; CI: 0.47-11.01, $p=0.308$ ).

\section{Discussion}

This study provides the first empirical evidence of herbal medicine use during breastfeeding in Sierra Leone, and the first detailed insights in Africa. This study found that over one-third of women used herbal medicine during breastfeeding, which is lower than the prevalence of use reported in similar studies conducted in Australia [13], Taiwan [12] and Italy [14]. A possible reason for such variation is the difference in definition of herbal medicine - for example, while herbal teas may be included as herbal medicines in some countries, they may not be considered herbal treatments as much as foods in places like Taiwan and others [42]. It may also be due to differences in respondents' ethnic background. For instance, an Australian study on use of herbal medicine during breastfeeding surveyed a multi-ethnic sample many of which were from an Asian background and that contribute to high use of herbal medicine [13]. Non-disclosure of herbal medicine use to researchers may have also been an issue, particularly considering hesitance to disclose herbal medicine use to conventional health practitioners was so high among women participating in this study. Nevertheless, results from this study demonstrate that herbal medicine use during breastfeeding is relatively common among mothers visiting public healthcare facilities in Sierra Leone, and should be considered during conventional health consultations. Low cost, accessibility and perceived efficacy and safety, dissatisfaction with the healthcare system and cultural acceptance might explain the reason for high use in our study, as it has been reported in other studies [43, 44].

One key finding is that breastfeeding mothers did not commonly use herbal medicines to augment their breastmilk production. Instead, they were used mainly to treat a variety of other health conditions. Our result is lower than that reported by similar study conducted in Australia [13] in which nearly one quarter of users consumed herbal medicine to increase breast milk production. The use of herbal medicines during breastfeeding for reasons other than to augment breast milk production is supported by the fact that the two major herbal medicines used in our study were Cassia sieberiana and Luffa acutangula. Recent research has reported Cassia Sieberiana is mostly sold in Sierra Leone as a herbal remedy for the treatment of stomach ache and febrile illness [45]. Preclinical studies on Cassia sieberiana suggest its major mechanism of action is mediated via anti-ulcerogenic properties [46], which may explain its indication for stomach ache as 


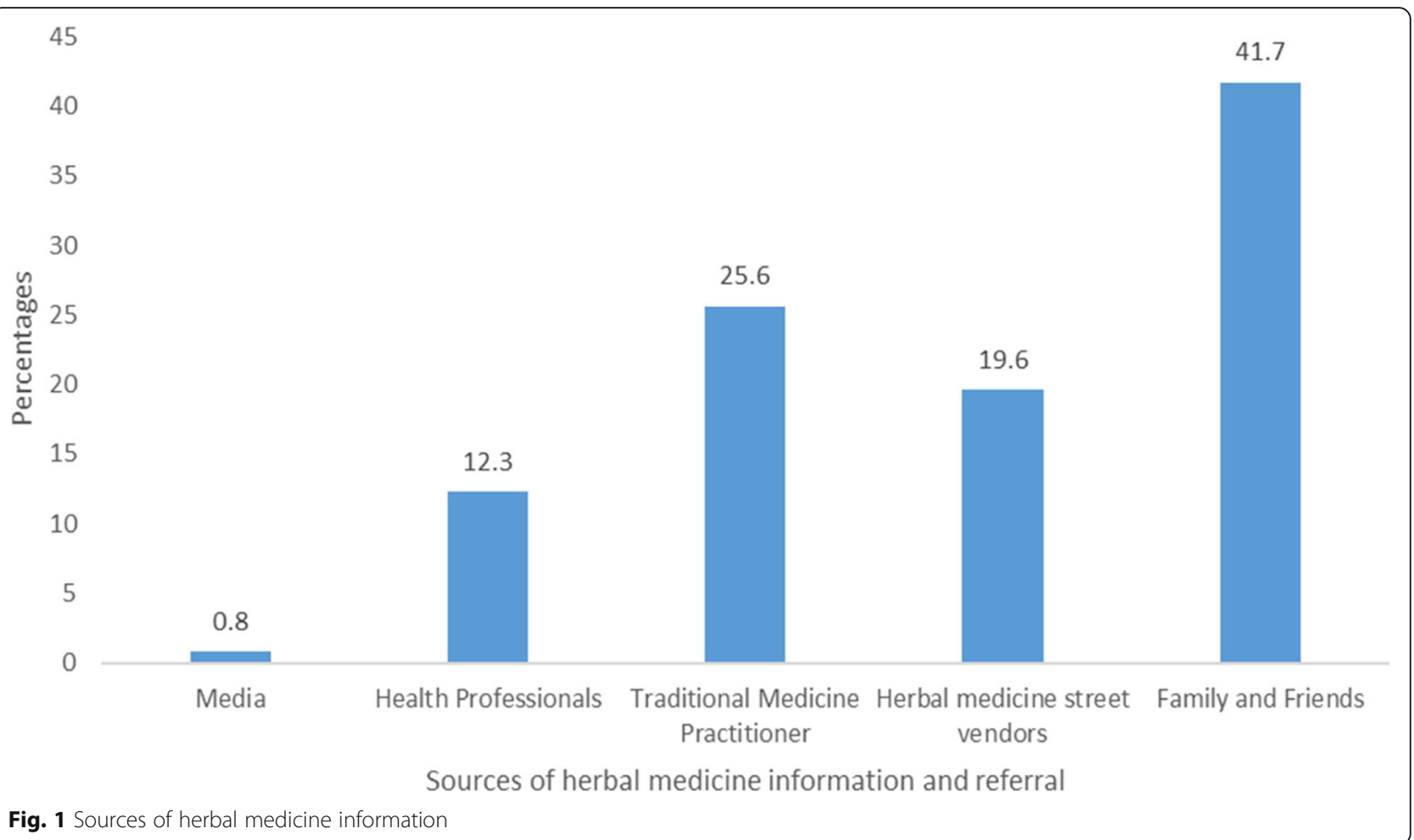

reported in our study. However, animal studies have uncovered the potential of C.sieberiana to cause liver and kidney toxicity at both low and high doses [47], highlighting the potention for herbal medicines to have adverse effect. In this case, such effects can potentially cause harm

Table 3 Other products or special diet used by lactating mothers to augment Breastmilk production and supply

\begin{tabular}{lll}
\hline $\begin{array}{l}\text { Use of special diet to } \\
\text { increase breast milk } \\
\text { production }(n=378)\end{array}$ & Yes & No \\
$\begin{array}{l}\text { If yes, Was it useful } \\
(n=355)\end{array}$ & Yes & 23(6.1) \\
$\begin{array}{l}\text { If yes, was it safe } \\
\text { to use }(n=355)\end{array}$ & Yes & $355(100)$ \\
\hline
\end{tabular}

If yes, type of special diet

\begin{tabular}{|c|c|}
\hline $\begin{array}{l}\text { Cassava leaves } \\
\text { sauce \& tubers }\end{array}$ & 286 \\
\hline $\begin{array}{l}\text { Peanuts \& peanuts } \\
\text { sauce }\end{array}$ & 43 \\
\hline Potato leaves sauce & 32 \\
\hline Sesame Sauce & 34 \\
\hline Rice & 19 \\
\hline Beans sauce & 11 \\
\hline $\begin{array}{l}\text { Others (banana, fish, } \\
\text { egg, coconut, milk, } \\
\text { wheat, maize and tea) }\end{array}$ & 10 \\
\hline
\end{tabular}

to the mother and baby. Whilst not commonly used to increase breast-milk production, our study indicates that herbal medicines may be used to 'cleanse' initial breast milk. Previous qualitative research examining the use of herbal medicine for pediatric conditions in the northern region of Sierra Leone found that women also described the "cleansing of breast milk" as an indication for herbal medicine use [48]. A study in Kenya has reported that some women refused to breastfeed their children immediately after birth because they considered the breast milk produced to be dirty or can cause disease [25]. This might explain the indication for L.acutangula, which is commonly used as a diuretic, expectorant, laxative, and purgative agent [49].

Another important point from our results is the high utilization of herbal medicine observed in women attending subsidised or free conventional medical services provided by the FHCI. This finding implies that even though the FHCI has removed access and cost barriers [32] that may have made TCAM more attractive (as a cheaper option than non-subsidised conventional services), improved accessibility of conventional health services has not changed the health-seeking behaviour of these women with respect to non-conventional services. One potential explanation for this may be the inherently weak monitoring system that allows conventional healthcare providers to demand money for their services [33]. Adherence to strong cultural beliefs and practices that considered herbal remedies to be natural and therefore safe and effective may also 
Table 4 Top most commonly used herbal medicines during breastfeeding (in descending order of popularity)

\begin{tabular}{|c|c|c|c|c|c|}
\hline $\begin{array}{l}\text { Common/local } \\
\text { name of herbal } \\
\text { medicine }\end{array}$ & $\begin{array}{l}\text { Botanical/Scientific } \\
\text { name }\end{array}$ & $\begin{array}{l}\text { Numbers(\%)reporting } \\
\text { use of this herb } \\
(N=181)\end{array}$ & Recommended by & $\begin{array}{l}\mathrm{n} \text { of specific } \\
\text { herb users) } \\
\text { who believed } \\
\text { the herb was } \\
\text { helpful }\end{array}$ & $\begin{array}{l}\text { Indication for use } \\
\text { (n(\%) of specific } \\
\text { herb users) }\end{array}$ \\
\hline Bitter medicine(Gbangba) & $\begin{array}{l}\text { Cassia sieberiana } \\
\text { DC. }\end{array}$ & $66(36.5)$ & $\begin{array}{l}\text { Relative(32),myself(21),friends(4),neighbour(2), } \\
\text { health worker(2), in-law(1), mate(1) }\end{array}$ & 64 & $\begin{array}{l}\text { Stomach ache } 58(84.1) \text {, } \\
\text { malaria } 9(13.0), \text { breast } \\
\text { milk production } 2(2.9)\end{array}$ \\
\hline Rabena & $\begin{array}{l}\text { Luffa acutangula } \\
\text { (L.) Roxb. }\end{array}$ & $53(29.3)$ & $\begin{array}{l}\text { Relative(33), myself(13), friend (2), } \\
\text { neighbour(2), family(1) health } \\
\text { worker(1), herbalist(1) }\end{array}$ & 53 & $\begin{array}{l}\text { Cleansing of the breast } \\
\text { against contaminated } \\
\text { milk29(54.7),gynaecological } \\
\text { infections 20(37.7) } \\
\text { stomach-ache3(5.7), } \\
\text { malaria 6(11.8) }\end{array}$ \\
\hline Lemon grass & $\begin{array}{l}\text { Cymbopogon } \\
\text { citratus (DC.) Stapf }\end{array}$ & $6(3.3)$ & Relative(5),myself(1) & 6 & $\begin{array}{l}\text { General Wellbeing (3), } \\
\text { Stomach ache }(1) \text {, } \\
\text { malaria(1), common } \\
\text { cold(1) }\end{array}$ \\
\hline Moringa & $\begin{array}{l}\text { Moringa oleifera } \\
\text { Lam. }\end{array}$ & $6(3.3)$ & Relative (4), myself(1), friend(1) & 6 & $\begin{array}{l}\text { Stomach ache(3), General } \\
\text { Wellbeing (2), malaria(1) }\end{array}$ \\
\hline Garlic & Alium sativum $L$ & $5(2.8)$ & Myself (2), family (1) & 5 & $\begin{array}{l}\text { General Wellbeing } \\
\text { cough, cold }\end{array}$ \\
\hline Tea bush & Camellia sinensis & $2(1.1)$ & Relative \& neighbour & 2 & $\begin{array}{l}\text { General Wellbeing, } \\
\text { Fungal Infection }\end{array}$ \\
\hline Pawpaw leaves & Carica papaya & $2(1.1)$ & Myself & 2 & $\begin{array}{l}\text { stimulate Breast milk } \\
\text { production }\end{array}$ \\
\hline
\end{tabular}

Table 5 Independent predictors of herbal medicine use among lactating mothers

\begin{tabular}{|c|c|c|c|c|c|}
\hline Predictors & Variables & Crude Odd ratio $(95 \% \mathrm{Cl})$ & $p$-value & Adjusted Odd ratio (95\% Cl) & $p$-value \\
\hline \multirow[t]{2}{*}{ Place of Origin } & Western Area & 1 & 0.069 & 1 & \\
\hline & Outside of Western Area & $2.23(0.94-5.30)$ & & - & \\
\hline \multirow[t]{4}{*}{ Educational status } & Tertiary & 1 & & 1 & \\
\hline & Non-formal & $2.36(1.00-5.55)$ & 0.049 & $2.02(0.85-4.82)$ & 0.111 \\
\hline & Primary & $2.72(0.82-9.04)$ & 0.101 & $2.50(0.74-8.47)$ & 0.141 \\
\hline & Secondary & $2.36(1.03-5.43)$ & 0.043 & $1.98(0.85-4.61)$ & 0.115 \\
\hline \multirow[t]{2}{*}{ Age of child in months } & $0-6$ months & 1 & & 1 & \\
\hline & 7-12 months & $1.96(1.25-3.08)$ & 0.003 & $1.80(1.13-2.85)$ & 0.013 \\
\hline \multirow[t]{2}{*}{ Is this your first child you have given birth to? } & Yes & 1 & & 1 & \\
\hline & No & $1.44(0.94-2.20)$ & 0.093 & - & \\
\hline \multirow[t]{2}{*}{ Child health status } & Healthy & 1 & & 1 & \\
\hline & Sick & $1.55(1.01-2.39)$ & 0.044 & $1.30(0.83-2.04)$ & 0.253 \\
\hline \multirow[t]{2}{*}{ Mother perceived health status } & Healthy & 1 & & 1 & \\
\hline & Sick & $2.04(0.67-6.18)$ & 0.210 & - & \\
\hline \multirow[t]{2}{*}{ Living with your parent or partner's parent } & Yes & 1 & & 1 & \\
\hline & No & $0.74(0.48-1.14)$ & 0.166 & - & \\
\hline \multirow{2}{*}{$\begin{array}{l}\text { Herbal medicine is effective than conventional } \\
\text { medicine }\end{array}$} & Disagree & 1 & & 1 & \\
\hline & Agree & $1.77(1.10-2.84)$ & 0.019 & $2.27(0.47-11.01)$ & 0.308 \\
\hline \multirow{2}{*}{$\begin{array}{l}\text { Herbal medicine is safer than conventional } \\
\text { medicine }\end{array}$} & Disagree & 1 & & 1 & \\
\hline & Agree & $1.70(1.05-2.74)$ & 0.031 & $0.66(0.13-3.26)$ & 0.606 \\
\hline
\end{tabular}


influence continued use $[44,50]$. Mistrust in the current healthcare system [33], attitude of healthcare providers and women's understanding of health and disease might play a role in their pluralistic pattern of seeking healthcare. Although these factors have been reported elsewhere in Africa [51], further research is required to fully understand the enablers of the health seeking behaviour currently being practiced within the milieu of the FHCI in Sierra Leone. However, maternal healthcare professionals should consider these issues when communicating with their patients as it has the potential to impact the health of the mother and baby [19].

A more focused approach to TCAM use in breastfeeding should also be encouraged as some herbal medicines may interact with conventional pharmaceutical medications [18] and or act as contaminants that can lead to adverse health outcomes for both mother and child $[19,52]$. Results from our study indicate that breastfeeding women use herbal medicines concurrently with conventional care, rather than as an alternative, which may increase the risks associated with unforeseen interactions. Results from our study also indicate that breastfeeding women may be hesitant to disclose this use voluntarily. However, with evidence of high usage of herbal medicines in the breastfeeding population, it is essential that healthcare providers treating this population are aware of, and ask about, TCAM practices their patients might be using including the benefits and harm associated with this use. This, in turn, will put them in the position to provide evidence-based information with regards the rational use of herbal medicine when breastfeeding that maximise benefits and minimise the risks.

In our study, dietary amendments were used to increase breast milk supply more commonly than herbal medicines. To increase milk production or supply, the majority of women in our study used local dietary sources such as cassava leaves and groundnut soup sauce. However, such use appears as a result of the belief that these diets are good at helping to increase milk production or supply in women. The use of dietary sources as galactogogues might be linked to the unavailability of known herbal galactogogues such as fenugreek [53] in Sierra Leone. Whilst most galactagogue studies have focused on herbal medicines [54], the preference for dietary approaches observed in this study may indicate that dietary sources may also proffer a fruitful area for further research in the search for treatments for insufficient milk production.

Our study found that mothers whose child is more than 6 months old were more likely to use herbal medicine than those with children were 6 months old or less. This could be associated with a number of factors. Mothers may be concerned that younger infants are more likely to experience overdose or adverse events from indirect ingestion of herbal medicine [13], Such safety concern of lactating mothers for their children is often expressed in the early stage of breastfeeding for conventional treatments [55]. Also, for women that used herbal medicine, we speculate that they might have used it to treat their own conditions and maintaining their own health and wellbeing. It may also indicate that women may overlook symptoms for the first few post-partum months, but seek treatment for conditions if the symptoms remain long-standing or unresolved. This speculation is supported by our finding that the indications for use of most of the herbal medicines were not breastfeeding related (Table 4).

The majority of mothers in this study did not disclose their use of herbal medicine to their healthcare provider, even though close to half of mothers in this study reported that their health care provider asked them. This non-disclosure behavior is similar to findings of a study carried out in Western Australia [13] and among pregnant women in Kenya [35], Uganda [56] and Ethiopia [15]. The primary reason for non-disclosure was that respondents thought it was not necessary to inform their healthcare provider of herbal medicine use; a similar reason put forward in a South African study [57]. Perceptions of herbal medicine being naturally safe - and therefore not particularly relevant to medical discussion - might partly explain this attitude [58]. Fear of health provider's reaction to herbal medicine use, the potential undermining of the relationship and trust between patient and practitioner and the absence of any personal as well as cultural connection with conventional medicine compared to TCAM have also been put forward as potential reasons for non-disclosure [59]. Given that herbal medicines are not always used safely $[16,60]$, better care to mothers will be enhanced if healthcare providers proactively seek to know their patients' herbal-drug use status and discuss both potential harms and benefits associated with the concurrent use of both types of medicines in breastfeeding [61]. Further studies are required that investigate obstacles to effective communication about herbal medicine use between mothers and their healthcare providers as well as the impact of such discussion on patient health outcome. Nevertheless, it is critical that an open dialogue, devoid of prejudice, is initiated by healthcare providers and patients on herbal medicine use. It is likely that patients will adhere to their healthcare providers' advice [62] and that could prevent potential adverse drug effects and herbal -drug interactions.

We observed in this study that TCAM practitioners, relatives and friends serve as a source of information and referral for herbal medicine use among breastfeeding women. This result corroborates with findings reported in a Ghanaian study [63]. In most cases TCAM 
practitioners influence patient choice of therapy by making unproven claims about their herbal preparations that are often not well labeled and standardized [64, 65]. Also,TCAM practitioners and family members are mostly unaware of the probable risk associated with the herbs they are recommending to their patients or relatives [66, 67]. Most herbal medicine research investigating safety during breastfeeding has focused on herbs which are specifically used for augmenting breast milk production (e.g. galactogogues) [17]. Results from our study suggest this narrow focus is insufficient, as breastfeeding mothers may be using a variety of herbal medicines unrelated to breastfeeding potentially because they believe herbal medicines may be safer than pharmaceutical equivalents at this time. As such, research to establish evidence-based knowledge of herbal medicine use during breastfeeding - irrespective of their specific indication for augmenting breast milk production is urgently needed. Also, the need for regulatory guidelines for TCAM practice including the advertisement and labeling of their products is required to ensure consumers do not receive misleading information. Furthermore, the introduction of TCAM content in all healthcare practitioner training programs and also as part of the continuous professional training will improve the knowledge level of allopathic health professionals on TCAM therapies which may help them provide better advice to mothers on the appropriate use of herbal medicines.

\section{Limitations}

Since we employed a cross-sectional design and self-report was used to assess herbal medicine use in this study, there is a possibility of under-reporting or over-reporting of the prevalence of use. Also, it was impossible to establish a trend or a clear causal effect [68]. The possibility that respondent might not have been truthful in their response (social desirability bias) should be considered in our study. In addition, our study fails to look at the reasons why women utilize herbal medicine despite receiving free healthcare service in public health facilities. Further research should look into this area. Further, our study was conducted in an urban and peri-urban setting, which makes findings not generalizable for the whole of Sierra Leone, especially for rural areas.

\section{Conclusion}

Our study concludes that herbal medicine use among lactating mothers visiting public health facilities in the western area of Sierra Leone is common although not as an herbal galactagogue. Instead, local dietary substances were used by most mothers to increase the production and supply of breast milk. The practice of medical pluaralism by mothers in our study makes the potential for adverse health outcome for both the mother and child to be high. Therefore, it is of public health interest that healthcare providers need to familiarise themselves with current knowledge on the benefits and risk associated with the commonly used herbal products among this group of women and be proactive in initiating dialogue on the rational use of these medicines.

\section{Additional file}

Additional file 1: Questionnaire on the use of herbal medicine during lactation in western area of Sierra Leone. (DOCX 92 kb)

\section{Abbreviations}

COMAHS-USL: College of medicine and Allied health Sciences, University of Sierra Leone; FHCl: Free healthcare initiative; TCAM: Traditional,

complementary and alternative medicine; TM: Traditional medicine

\section{Acknowledgements}

We would like to thank the dean faculty of Pharmaceutical Science COMAHS-USL and the management of the health facilities involved in this study for creating the enabling environment for data collection. Successful completion of this manuscript was made possible through participation in the Twelve Weeks to Publication Program funded by Faculty of Health, University of Technology Sydney and with the active support and contributions made by the facilitators and other program participants.

\section{Funding}

This research did not receive any specific grant from funding agencies in the public, commercial, or not-for-profit sectors.

Availability of data and materials

The materials and data of this study are available from the corresponding author upon request.

\section{Authors' contributions}

PBJ conceived of the study, contributed to the design, analyzed, interpreted the data, and wrote the manuscript draft. AlK contributed to the study design, data collection and the contributed in the intellectual content. AJB, JW and AS contributed to the study design and intellectual content of the manuscript. All authors read and approved the final version of the manuscript.

\section{Ethics approval and consent to participate}

The research and ethics committee of College of Medicine and Allied Health Sciences, University of Sierra Leone (COMAHS-USL) gave ethical approval before the start of the study. Participation in the study was voluntary. Either signing or thumb printing the consent form indicated their agreement to participate in the study.

\section{Consent for publication}

Not applicable.

\section{Competing interests}

Jon Wardle and Amie Steel are associate editors of BMC Complementary and alternative Medicine. The other authors have no conflict of interest whatsoever.

\section{Publisher's Note}

Springer Nature remains neutral with regard to jurisdictional claims in published maps and institutional affiliations.

\section{Author details}

${ }^{1}$ Australian Research Centre in Complementary and Integrative Medicine, Faculty of Health, University of Technology Sydney, Ultimo, Sydney, NSW 2007, Australia. ${ }^{2}$ Faculty of Pharmaceutical Sciences, College of Medicine and Allied Health Sciences, University of Sierra Leone, Freetown, Sierra Leone. ${ }^{3}$ Faculty of Basic Medical Sciences, College of Medicine and Allied Health Sciences, University of Sierra Leone, Freetown, Sierra Leone. ${ }^{4}$ Endeavour College of Natural Health, 269 Wickham St, Fortitude Valley, QLD 4006, Australia. 
Received: 10 July 2018 Accepted: 11 March 2019

Published online: 15 March 2019

\section{References}

1. World Health Organisation. WHO Traditional Medicine Strategy 2014-2023. Geneva: World Health Organization; 2013.

2. Onyiapat J-IE, Okoronkwo IL, Ogbonnaya NP. Complementary and alternative medicine use among adults in Enugu, Nigeria. BMC Complement Altern Med. 2011:11:19.

3. Okoronkwo I, Onyia-pat J-I, Okpala P, Agbo M-A, Ndu A. Patterns of complementary and alternative medicine use, perceived benefits, and adverse effects among adult users in Enugu urban, Southeast Nigeria. Evid Based Complement Alternat Med. 2014;2014.

4. Bodeker G, Kronenberg F. A public health agenda for traditional, complementary, and alternative medicine. Am J Public Health. 2002;92(10):1582-91.

5. Z Zhang Y, Leach MJ, Hall H, Sundberg T, Ward L, Sibbritt D, Adams J. Differences between male and female consumers of complementary and alternative medicine in a national US population: a secondary analysis of 2012 NIHS data. Evid Based Complement Alternat Med. 2015;2015:10.

6. Alwhaibi M, Sambamoorthi U. Sex differences in the use of complementary and alternative medicine among adults with multiple chronic conditions. Evid Based Complement Alternat Med. 2016;2016:8.

7. Achigbu E, Achigbu K. Traditional medication use among out-patients attending the eye clinic of a secondary health facility in Owerri, south-East Nigeria. Orient Journal of Medicine. 2014;26(3-4):107-13.

8. Kaadaaga HF, Ajeani J, Ononge S, Alele PE, Nakasujja N, Manabe YC, Kakaire O. Prevalence and factors associated with use of herbal medicine among women attending an infertility clinic in Uganda. BMC Complement Altern Med. 2014;14(1):27.

9. Laelago T, Yohannes T, Lemango F. Prevalence of herbal medicine use and associated factors among pregnant women attending antenatal care at public health facilities in Hossana Town, Southern Ethiopia: facility based cross-sectional study. Archives of Public Health. 2016;74(1):7.

10. Steenkamp V. Traditional herbal remedies used by south African women for gynaecological complaints. J Ethnopharmacol. 2003;86(1):97-108.

11. Addo V. Herbal medicines: socio-demographic characteristics and pattern of use by patients in a tertiary obstetrics and gynaecology unit. J Sci Technol (Ghana). 2007;27(3):149-55.

12. Chuang C-H, Chang P-J, Hsieh W-S, Tsai Y-J, Lin S-J, Chen P-C. Chinese herbal medicine use in Taiwan during pregnancy and the postpartum period: a population-based cohort study. Int J Nurs Stud. 2009;46(6):787-95.

13. Sim TF, Sherriff J, Hattingh HL, Parsons R, Tee LBG. The use of herbal medicines during breastfeeding: a population-based survey in Western Australia. BMC Complement Altern Med. 2013;13:317

14. Aleandri V, Bertazzoni G, Romanzi D, Vetrano G, Durazzi F, Mazzanti G, Vitalone A. The use of herbal products during breastfeeding: a study from a public Italian hospital. J Food Process Technol. 2014;5(354):2.

15. Mekuria AB, Erku DA, Gebresillassie BM, Birru EM, Tizazu B, Ahmedin A. Prevalence and associated factors of herbal medicine use among pregnant women on antenatal care follow-up at University of Gondar referral and teaching hospital, Ethiopia: a cross-sectional study. BMC Complement Altern Med. 2017;17(1):86.

16. Fakeye TO, Adisa R, Musa IE. Attitude and use of herbal medicines among pregnant women in Nigeria. BMC Complement Altern Med. 2009;9(1):53.

17. Budzynska K, Gardner ZE, Dugoua J-J, Low Dog T, Gardiner P. Systematic review of breastfeeding and herbs. Breastfeed Med. 2012;7(6):489-503.

18. Tsai HH, Lin HW, Simon Pickard A, Tsai HY, Mahady GB. Evaluation of documented drug interactions and contraindications associated with herbs and dietary supplements: a systematic literature review. Int J Clin Pract. 2012;66(11):1056-78

19. Chien L-C, Yeh C-Y, Lee H-C, Chao HJ, Shieh M-J, Han B-C. Effect of the mother's consumption of traditional Chinese herbs on estimated infant daily intake of lead from breast milk. Sci Total Environ. 2006;354(2):120-6.

20. Ebrahim AM, Eltayeb MH, Khalid H, Mohamed H, Abdalla W, Grill P, Michalke B. Study on selected trace elements and heavy metals in some popular medicinal plants from Sudan. J Nat Med. 2012;66(4):671-9.

21. Gatti L. Maternal perceptions of insufficient Milk supply in breastfeeding. J Nurs Scholarsh. 2008:40(4):355-63.

22. Jackson P. Complementary and alternative methods of increasing breast milk supply for lactating mothers of infants in the NICU. Neonatal Network 2010;29(4):225-30
23. Foda MI, Kawashima T, Nakamura S, Kobayashi M, Oku T. Composition of milk obtained from unmassaged versus massaged breasts of lactating mothers. J Pediatr Gastroenterol Nutr. 2004;38(5):484-7.

24. Sibeko L, Dhansay MA, Charlton KE, Johns T, Gray-Donald K. Beliefs, attitudes, and practices of breastfeeding mothers from a Periurban Community in South Africa. J Hum Lact. 2005;21(1):31-8.

25. Kimani-Murage EW, Wekesah F, Wanjohi M, Kyobutungi C, Ezeh AC, Musoke RN, Norris SA, Madise NJ, Griffiths P. Factors affecting actualisation of the WHO breastfeeding recommendations in urban poor settings in Kenya. Matern Child Nutr. 2015;11(3):314-32.

26. Ranasinghe S, Ansumana R, Lamin JM, Bockarie AS, Bangura U, Buanie JA, Stenger DA, Jacobsen $\mathrm{KH}$. Herbs and herbal combinations used to treat suspected malaria in Bo, Sierra Leone. J Ethnopharmacol. 2015:166:200-4.

27. Diaz T, George AS, Rao SR, Bangura PS, Baimba JB, McMahon SA, Kabano A. Healthcare seeking for diarrhoea, malaria and pneumonia among children in four poor rural districts in Sierra Leone in the context of free health care: results of a cross-sectional survey. BMC Public Health. 2013;13(1):157.

28. James PB, Bah AJ, Tommy MS, Wardle J, Steel A. Herbal medicines use during pregnancy in Sierra Leone: an exploratory cross-sectional study. Women Birth. 2017

29. James PB, Kamara H, Bah AJ, Steel A, Wardle J. Herbal medicine use among hypertensive patients attending public and private health facilities in Freetown Sierra Leone. Complement Ther Clin Pract. 2018;31:7-15.

30. James PB, Bah AJ, Kondorvoh IM. Exploring self-use, attitude and interest to study complementary and alternative medicine (CAM) among final year undergraduate medical, pharmacy and nursing students in Sierra Leone: a comparative study. BMC Complement Altern Med. 2016;16(1):121.

31. James PB, Bah AJ. Awareness, use, attitude and perceived need for complementary and alternative medicine (CAM) education among undergraduate pharmacy students in Sierra Leone: a descriptive crosssectional survey. BMC Complement Altern Med. 2014;14(1):438.

32. Witter S, Brikci N, Harris T, Williams R, Keen S, Mujica A, Jones A, MurrayZmijewski A, Bale B, Leigh B. The Sierra Leone free health care initiative (FHCl): process and effectiveness review; 2016

33. Pieterse $P$, Lodge $T$. When free healthcare is not free. Corruption and mistrust in Sierra Leone's primary healthcare system immediately prior to the Ebola outbreak. Int Health. 2015;7(6):400-4

34. Macfoy C. Medicinal plants and traditional medicine in Sierra Leone. Indiana, U.S.A: iUniverse LLC; 2013.

35. Mothupi MC. Use of herbal medicine during pregnancy among women with access to public healthcare in Nairobi, Kenya: a cross-sectional survey. BMC Complement Altern Med. 2014;14(1):432.

36. Nordeng H, Al-Zayadi W, Diallo D, Ballo N, Paulsen BS. Traditional medicine practitioners' knowledge and views on treatment of pregnant women in three regions of Mali. J Ethnobiol Ethnomed. 2013:9(1):67.

37. Suroowan S, Mahomoodally F. Complementary and alternative medicine use among Mauritian women. Complement Ther Clin Pract. 2013;19(1):36-43

38. Statistics Sierra Leone. Sierra Leone 2015 Population and Housing Census. Provisional Results. Freetown Sierra Leone: Statistics Sierra Leone; 2016.

39. Sim TF, Hattingh HL, Sherriff J, Tee LBG. Perspectives and attitudes of breastfeeding women using herbal galactagogues during breastfeeding: a qualitative study. BMC Complement Altern Med. 2014;14(1):216.

40. Turay BMS. Medicinal plants of Sierra Leone: a compendium: University of Alberta; 1997.

41. Conservatoire et Jardin botaniques de la Ville de Genève and South African National Biodiversity Institute, Pretoria. http://www.ville-ge.ch/musinfo/bd/ cjb/africa/index.php?langue=an.

42. Chau CF, Wu SH. The development of regulations of Chinese herbal medicines for both medicinal and food uses. Trends Food Sci Technol. 2006;17(6):313-23.

43. Olisa NS, Oyelola FT. Evaluation of use of herbal medicines among ambulatory hypertensive patients attending a secondary health care facility in Nigeria. Int J Pharm Pract. 2009;17(2):101-5.

44. Okafor I, Sekoni A, Ezeiru S, Ugboaja J, Inem V. Orthodox versus unorthodox care: a qualitative study on where rural women seek healthcare during pregnancy and childbirth in southwest, Nigeria. Malawi Med J. 2014;26(2):45-9.

45. Jusu A, Sanchez AC. Economic importance of the medicinal plant trade in Sierra Leone. Econ Bot. 2013;67(4):299-312.

46. Nartey ET, Ofosuhene M, Kudzi W, Agbale CM. Antioxidant and gastric cytoprotective prostaglandins properties of Cassia sieberiana roots bark 
extract as an anti-ulcerogenic agent. BMC Complement Altern Med. 2012;12(1):65.

47. Obidah W, Sarsquo U, Wurochekke A. Toxic effects of aqueous stem bark extract of Cassia sieberiana on some biochemical parameters in rats. Afr J Biochem Res. 2009;3(5):229-31.

48. Bakshi SS, McMahon S, George A, Yumkella F, Bangura P, Kabano A, Diaz T. The role of traditional treatment on health care seeking by caregivers for sick children in Sierra Leone: results of a baseline survey. Acta Trop. 2013; 127(1):46-52.

49. Manikandaselvi S, Vadivel V, Brindha P. Review on Luffa acutangula L: ethnobotany, Phytochemistry, nutritional value and pharmacological properties. Int J Curr Pharm Rev Res. 2016;7(3):151-5.

50. Birhan W, Giday M, Teklehaymanot T. The contribution of traditional healers' clinics to public health care system in Addis Ababa, Ethiopia: a crosssectional study. J Ethnobiol Ethnomed. 2011;7(1):39.

51. Aderibigbe S, Agaja S, Bamidele J. Determinants of utilization of traditional bone setters in Ilorin, north Central Nigeria. J Prev Med Hyg. 2013;54(1):35-40.

52. Hou Y, You J, Chang H. The differences of sheng-hua-tang on the postpartum recovery among normal spontaneous delivery, cesarean section and artifical abortion-the analytic studies of 34 gynecological experts' experiences in traditional Chinese medicine. J Chin Med (ROC). 2006;17(4): 127-34.

53. Zapantis A, Steinberg JG, Schilit L. Use of herbals as galactagogues. J Pharm Pract. 2012;25(2):222-31.

54. Bazzano AN, Hofer R, Thibeau S, Gillispie V, Jacobs M, Theall KP. A review of herbal and pharmaceutical Galactagogues for breast-feeding. Ochsner J. 2016;16(4):511-24.

55. Al-Sawalha NA, Tahaineh L, Sawalha A, Almomani BA. Medication use in breastfeeding women: a National Study. Breastfeed Med. 2016;11(7):386-91.

56. Lubinga S, Kintu A, Atuhaire J, Asiimwe S. Concomitant herbal medicine and antiretroviral therapy (ART) use among HIV patients in Western Uganda: a cross-sectional analysis of magnitude and patterns of use, associated factors and impact on ART adherence. AIDS Care. 2012;24(11):1375-83.

57. Singh V, Raidoo DM, Harries CS. The prevalence, patterns of usage and people's attitude towards complementary and alternative medicine (CAM) among the Indian community in Chatsworth, South Africa. BMC Complement Altern Med. 2004;4(1):3.

58. Vickers KA, Jolly KB, Greenfield SM. Herbal medicine: women's views, knowledge and interaction with doctors: a qualitative study. BMC Complement Altern Med. 2006;6:40.

59. Hughes G, Puoane T, Clark B, Wondwossen T, Johnson Q, Folk W. Prevalence and predictors of traditional medicine utilization among persons living with AIDS (PLWA) on antiretroviral (ARV) and prophylaxis treatment in both rural and urban areas in South Africa. Afr J Tradit Complement Altern Med. 2012;9(4):470-84.

60. Abodunrin OL, Omojasola T, Rojugbokan OO. Utilization of alternative medical services by people of a north central city of Nigeria. East Afr $J$ Public Health. 2011;8(2):82-7.

61. Tabuti J, Dhillion S, Lye K. Traditional medicine in Bulamogi county, Uganda: its practitioners, users and viability. J Ethnopharmacol. 2003;85(1):119-29.

62. Langlois-Klassen D, Kipp W, Rubaale T. Who's talking? Communication between health providers and HIV-infected adults related to herbal medicine for AIDS treatment in western Uganda. Soc Sci Med. 2008;67(1):165-76

63. Gyasi RM, Siaw LP, Mensah CM. Prevalence and pattern of traditional medical therapy utilisation in Kumasi metropolis and Sekyere south district, Ghana. J Ethnopharmacol. 2015;161:138-46.

64. Aziato L, Antwi HO. Facilitators and barriers of herbal medicine use in Accra Ghana: an inductive exploratory study. BMC Complement Altern Med. 2016; 16(1):142.

65. Gyasi RM, Mensah CM, Osei-Wusu Adjei P, Agyemang S. Public perceptions of the role of traditional medicine in the health care delivery system in Ghana. Global J Health Sci. 2011;3(2):40-9.

66. Ekor M. The growing use of herbal medicines: issues relating to adverse reactions and challenges in monitoring safety. Front Pharmacol. 2013;4.

67. Frawley J, Adams J, Broom A, Steel A, Gallois C, Sibbritt D. Majority of women are influenced by nonprofessional information sources when deciding to consult a complementary and alternative medicine practitioner during pregnancy. J Altern Complement Med. 2014;20(7):571-7.

68. Mann C. Observational research methods. Research design II: cohort, cross sectional, and case-control studies. Emerg Med J. 2003;20(1):54-60.

\section{Ready to submit your research? Choose BMC and benefit from:}

- fast, convenient online submission

- thorough peer review by experienced researchers in your field

- rapid publication on acceptance

- support for research data, including large and complex data types

- gold Open Access which fosters wider collaboration and increased citations

- maximum visibility for your research: over $100 \mathrm{M}$ website views per year

At BMC, research is always in progress.

Learn more biomedcentral.com/submissions 